\title{
ASSESSMENT OF URINARY IODINE LEVEL AND ITS RELATION TO THYROID FUNCTION IN SAMPLE OF EGYPTIAN PREGNANT FEMALES IN 1ST TRIMESTER
}

\author{
${ }^{1}$ Rania sayed Abd Elbaky, ${ }^{1}$ Merhan Samy Nasr, ${ }^{2}$ Ahmed Ali El Anwr, , ${ }^{1}$ Alyaa Abd \\ Elhameed Abd Elazeem \& ${ }^{1}$ Ahmed Mohamed Bahaa Eldin
}

\begin{abstract}
:
${ }^{1}$ Department of Internal

Medicine- Diabetes \&

Endocrinology, ${ }^{2}$ Department of

Gyncology and Obstetric, Faculty

of Medicine, Ain Shams

University, Cairo, Egypt.

Corresponding author

Alyaa Abd Elhameed Abd

Elazeem

Mobile: (+2) 01112550056

E.mail:

dralyaa2013@yahoo.com

Received: 29/7/2021

Accepted: 20/8/2021

Online ISSN: 2735-3540

Background: Thyroid disorders are considered the second most common endocrine disorders affecting women during their reproductive years and can impact up to $4 \%$ of all pregnancies. Of all thyroid disorders, hypothyroidism is the most prevalent, impacting approximately 2- 3\% of all pregnancies. Hyperthyroidism is far less prevalent, impacting approximately $0.2 \%$ of all pregnancies.

Aim of the Work: To assess the level of urinary iodine in 1st trimester of pregnancy and its relation with thyroid hormones level and autoimmunity status.

Subjects and Methods: To elucidate this aim 100 healthy pregnant female in their 1st trimester of pregnancy were included in the study. They were collected from Obstetrics and Gynecology Department El Demerdash hospital and Dar El shefa Hospital in the period from September, 2020 to November, 2020.

Results: Median urinary iodine was 55(41.0-76.0) $\mu \mathrm{g} / \mathrm{l}$ and their was 99 females had insufficient iodine intake less than $150 \mu \mathrm{g} / \mathrm{l}$, one had adequate intake (150-249) $\mu \mathrm{g} / l$ and none showed more than necessary intake (250-499) $\mu \mathrm{g} / \mathrm{l}$ or excessive intake more than $500 \mu \mathrm{g}$ /l. As regard thyroid ultrasound there was normal Thyroid volume in 94 subjects,(94.0\%)., increased volume in 6 subjects (6\%). There was a Significant negative correlation between each of the following the age and the gestational age; and urinary iodine

Conclusion: There was a significant iodine deficiency in pregnant women within the study area, indicating that some women may need to increase their iodine intake during pregnancy. Additionally, diagnosis and treatment of thyroid dysfunction during pregnancy should be based on pregnancy and method specific reference intervals, and more detailed staging is needed to assess pregnant women's thyroid function.
\end{abstract}

Keywords: Recommended Dietary Allowance, Median urinary iodine, iodine deficiency, pregnancy

\section{INTRODUCTION:}

Normal thyroid activity varies dramatically during pregnancy, with a twoto threefold rise in thyroxine-binding globulin concentrations, a 30-100\% increase in total triiodothyronine and thyroxine concentrations, and enhanced iodide clearance. In addition, hCG has a little thyroid stimulating effect. Pregnancy causes an increase in thyroid activity overall, allowing a healthy person to maintain a net euthyroid condition. In pregnant women, 
however, both hyperthyroidism and hypothyroidism can develop ${ }^{(1)}$.

Iodine is a natural element. Iodine is required for the normal functioning of our thyroid gland. Some meals, dietary supplements, medicines, and topical disinfectants include iodine. When a woman is pregnant or breastfeeding, her body requires extra iodine. The Recommended Dietary Allowance (RDA) for iodine in pregnant women is between 220 and 290 micrograms $(\mathrm{mcg})$, and $290 \mathrm{mcg}$ for nursing mothers ${ }^{(2)}$. Pregnant women should take iodine supplements containing 150 micrograms per day, according to the American Academy of Pediatrics (AAP) and the American Thyroid Association (ATA). Low thyroid hormone levels might be caused by low iodine levels in the body (hypothyroidism). Thyroid hormone levels that are too low during pregnancy might cause birth abnormalities. It might also raise the risk of preterm ${ }^{(3)}$.

"Severe iodine deficiency" is a term used to describe women who have extremely low iodine levels. Pregnancy might cause babies to be born with learning disabilities or hearing impairments. It's conceivable that a minor iodine deficit during pregnancy can cause learning and behavior issues. Iodine insufficiency and associated iodine deficiency illnesses affect an estimated 35 percent of the world's population, putting them at risk for iodine deficiency and related ailments. Iodine deficiency is dangerous throughout life, and has been linked to mental impairment and goitre in older children and adults, as well as pregnancy problems such as stillbirth and congenital abnormalities ${ }^{(4)}$.

Urinary iodine is a widely known, costeffective, and conveniently accessible iodine status indicator. Because the majority of iodine ingested by the body is eliminated in urine, it is regarded as a sensitive indicator of current iodine consumption and can reflect recent iodine status changes ${ }^{(5)}$.
Since urine iodine levels are not evenly distributed throughout the body, the median is the recommended method for determining their concentration ${ }^{(6)}$.

\section{AIM OF THE WORK}

The aim of work of the present study is to assess the level of urinary iodine in $1 \mathrm{st}$ trimester of pregnancy and its relation with thyroid hormones autoimmune thyroid profiles.

\section{SUBJECTS AND METHODS}

This cross sectional observational study was carried out in the period from September 2020 to November 2020. Our subjects were collected from the Obstetrics and Gynecology Department El Demerdash hospital and Dar El Shefa Hospital.

An informed consent was obtained from all participants in the study.

The study was conducted on 100 healthy pregnant female in their 1st trimester of pregnancy aged 18-40 years old.

Exclusion criteria: Acute illness, autoimmune disorders, diabetes Mellitus or hypertension. Patients with previous history or diagnosed with any thyroid disorder. Multiple pregnancies.

The following procedures were done for all patients participating in the study: Full history taking, including family history of thyroid disorders and/or other autoimmune diseases in first- and second-degree relatives, drug history of current and/or past use of antithyroid medication, levothyroxine replacement therapy, and/or radioiodine therapy; data on history of thyroid surgery and/or therapeutic head or neck irradiation; and data on current and/or past use of antithyroid medication, levothyroxine replacement therapy, and/or radioiodine therapy. 
Thorough clinical Examination: Vital signs (heart rate, temperature, respiratory rate, blood pressure). Anthropometric measurements including weight, height and abdominal waist circumference and body mass index (BMI) (weight/height ${ }^{2}$ per meter) Thyroid examination: An examination of the neck was done to assess the size of the thyroid gland by palpation

Laboratory assessment of: Thyroid functions (TSH, FT3,FT4) Antithyroglobulin. Abs by immunofluorescence assay. Anit-TPO Abs by immunofluorescence assay. Median urinary iodine estimation by spot urine sample (tryptophan ELISA Kit). WHO criteria for iodine deficiency: urinary iodine concentration $<150 \mathrm{microgram} / \mathrm{dl}$ is insufficient iodine intake (severe iodine deficiency).150-249 micro$\mathrm{gram} / \mathrm{dl}$ is adequate (adequate iodine nutrition). $250-499 \mu \mathrm{g} / \mathrm{dl}$ is above requirements. More than $500 \mu \mathrm{g} / \mathrm{dl}$ is excessive intake (risk of adverse health consequences) (WHO/NMH/NHD/EPG 2013)

Ultrasound examination: Neck ultrasound: Using a portable scanner with a highfrequency linier transducer of 7.5-10 $\mathrm{MHz}$. The volume of the thyroid gland was estimated using the method suggested by the World Health Organization $(\mathrm{V}(\mathrm{ml})=0.479$ xdxwx1 $(\mathrm{cm})$ ) for each lobe based on the depth, breadth, and length of each lobe. The thyroid volume measured was the total of the volumes of both lobes. The isthmus volume was not taken into account. Normal thyoid volume $6.60 .26 \mathrm{ml}$ (male 7.3) (female 6.4).

\section{Statistical analysis and package:}

Statistical package for Social Science was used to review, code, tabulate, and upload the obtained data to a computer (SPSS 20.0.1 for windows; SPSS Inc, Chicago, IL, 2001). According to the distribution of data, quantitative variables are reported as mean and standard deviation (SD) or median and interquartile range (IQR). Frequencies and percentages are used to convey qualitative characteristics. To compare a continuous variable between two research groups, the Student t test and Mann Whitney Test were employed. The connection between categorical variables was investigated using the Chi square test. A P-value probability of observing the association $<0.05$ was considered statistically significant, more than 0.05 non significant and less than 0.01 is highly significant. The correlation coefficient $\mathbf{r}$ ranges from -1.00 to +1.00 and it assess the existence, the direction and the strength of association.

\section{RESULTS:}

Our results showed that as regard the characteristics of demographic and anthropometric data: The mean of age was: $26.24 \pm 4.88$ year. The mean of gestational age was: $10.65 \pm 1.84$ week. The mean of weight (at beginning of pregnancy) was $70.78 \pm 9.02 \mathrm{~kg}$, the mean of height was: $161.84 \pm 6.96 \mathrm{~cm}$ and the mean of BMI was $26.95 \pm 2.21 \mathrm{~kg} / \mathrm{m}^{2}$ (table 1).

Laboratory findings showed that: Mean TSH was $1.9 \pm 0.98 \mathrm{mIU} / \mathrm{ml}$, Free $\mathrm{t} 3$ is $1.04 \pm 0.41 \mathrm{ng} / \mathrm{dl}$ and Free $\mathrm{t} 4$ is $3.02 \pm 0.68$ $\mathrm{ng} / \mathrm{dl}$ (table 2) and the percentage of subclinical hypothyroidism cases was $25 \%$ with Mean TSH $8.2 \pm 4.9 \mathrm{mIU} / \mathrm{ml}$, Ft4 $1.15 \pm 0.33 \mathrm{ng} / \mathrm{dl}$ and FT3 $2.91 \pm 0.63 \mathrm{ng} / \mathrm{dl}$ (table 3)

As regard autoimmune markersTPO $\mathrm{Ab}$ median was 8.3(4.4- 14.5) $\mathbf{~ m g / d l}$ and Thyroglobulin Ab median was: 54.5 (20.089.5) IU/ml (table 4)

Median Urinary Iodine was 55(41.076.0) $\mu \mathrm{g} / \mathbf{l}$ and the iodine was evaluated according to WHO scoring and their was 99 females had insufficient iodine intake (median urinary iodine less than $150 \mu \mathrm{g} / 1$ ), one had adequate intake( median urinary iodine150-249) $\mu \mathrm{g} / 1$ and none showed more than necessary intake( median urinary iodine 250-499) $\mu \mathrm{g} / \mathrm{l}$ or excessive intake 
more than (median urinary iodine $500 \mu \mathrm{g} / \mathrm{l}$ (table 5 )

As regard thyroid ultrasound there was normal Thyroid volume in 94 subjects, $(94.0 \%)$, increased volume in 6 subjects (6\%) subdivided into patients with thyroid solitary nodule in 4 subjects, $(4 \%)$

And patients with diffuse goitre in 2 subjects, $(2 \%)$ (Table 6) and urinary iodine in subjects with goitre (nodular or diffuse) was insufficient ( less than $150 \mu \mathrm{g} / \mathrm{dl}$ ) as same as all other subjects.

Correlation between median urinary iodine and the demographic and anthropometric data showed that:

There was a Significant negative correlation between the age and urinary iodine $(\mathrm{p}<0.05, \mathrm{r}-0,198)$, Significant negative Table (1): Baseline characteristics of demographic and anthropometric data of the studied patients.

\begin{tabular}{|l|c|c|}
\hline \multicolumn{1}{|c|}{ Parameter } & Mean \pm SD & Range \\
\hline Age(in years) & $26.24 \pm 4.88$ & $18.00-40.00$ \\
\hline Week of pregnancy & $10.65 \pm 1.84$ & $8.00-13.00$ \\
\hline Weight $(\mathrm{kg})$ & $70.78 \pm 9.02$ & $50.00-93.00$ \\
\hline Height $(\mathrm{in} \mathrm{cm})$ & $161.84 \pm 6.96$ & $150.00-175.00$ \\
\hline BMI $\left(\mathrm{kg} / \mathrm{m}^{2}\right)$ & $26.95 \pm 2.21$ & $20.03-31.07$ \\
\hline SBP $(\mathrm{mmHg})$ & $116.10 \pm 8.98$ & $100.00-135.00$ \\
\hline DBP $(\mathrm{mm} \mathrm{Hg})$ & $72.20 \pm 6.97$ & $60.00-85.00$ \\
\hline
\end{tabular}

This table shows that The mean of age was: $26.24 \pm 4.88$, The mean of gestational age was: $10.65 \pm 1.84$, The mean of weight (at beginning of pregnancy) was Table (2): Laboratory findings of the studied patients

\begin{tabular}{|l|l|l|}
\hline \multicolumn{1}{|c|}{ Parameter } & \multicolumn{1}{c|}{ Mean \pm SD } & \multicolumn{1}{c|}{ Range } \\
\hline TSH $\left(0.5 \_4\right) \mathrm{mIU} / \mathrm{ml}$ & $1.9 \pm 0.98$ & $0.20-11.00$ \\
\hline FT4 (0.8-1.76)ng/dl & $1.04 \pm 0.41$ & $0.00-1.90$ \\
\hline FT3 (2.3-4.2)ng/dl & $3.02 \pm 0.68$ & $1.00-4.20$ \\
\hline
\end{tabular}

This table shows that Mean TSH was1.9 \pm 0.98 . mIU/ml,Free $\mathrm{t} 3$ is $1.04 \pm 0.41 \mathrm{ng} / \mathrm{dl}$ and Free $\mathrm{t} 4$ is $3.02 \pm 0.68 \mathrm{ng} / \mathrm{dl}$

Table (3): Laboratory findings of the studied patients who have $\mathrm{SCH}$ (subclinical hypothyroidism)

\begin{tabular}{|l|c|c|}
\hline \multicolumn{1}{|c|}{ Parameter } & Mean SD & Range \\
\hline TSH(0.5_4)mIu/ml & $8.2 \pm 4.9$ & $4.3-23$ \\
\hline FT4(0.8_1.76)ng/dl & $1.15 \pm 0.33$ & $0.8-1.76$ \\
\hline FT3(2.3-4.2)ng/dl & $2.91 \pm 0.63$ & $2-4$ \\
\hline
\end{tabular}

This table shows the results of TSH $8.2 \pm 4.9 \mathrm{mIU} / \mathrm{ml}, \mathrm{Ft} 41.15 \pm 0.33 \mathrm{ng} / \mathrm{dl}$ subclinical hypothrodism cases with Mean correlation between the gestational age (in weeks) and urinary iodine ( $\mathrm{p}<0.05, \mathrm{r}-0.255)$, Non significant positive correlation between urinary iodine and BMI $(\mathrm{P}>0.05, \mathrm{r}$ 0.006).,SBP (P>0.05, $\mathrm{r}$ 0.113) and Non significant negative correlation between 0.089), height ( $\mathrm{p}>0.05, \mathrm{r}-0.139)$ and ,DBP Correlation between median urinary iodine and laboratory findings :

Significant positive correlation between urinary iodine and thyroglobin antibody $(p<0.05)$ (figure 4). Non significant positive correlation between urinary iodine and $\mathrm{f}$ T4 (>p0.05, non significant negative correlation between urinary iodine and TSH., FT3, (>p0.05) TPO (>P0.05) (table8).

$70.78 \pm 9.02$, The mean of height was: $161.84 \pm 6.96$ and The mean of BMI was $26.95 \pm 2.21$ (table 1) urinary iodine and Weight $(\mathrm{p}>0.05, \mathrm{r}$ 0.- 
Table (4): The table showing autoimmune thyroid markers of the studied patients.

\begin{tabular}{|l|c|c|}
\hline \multicolumn{1}{|c|}{ Parameter } & Median & IQR \\
\hline TPO antibody (up to 34)mg/l & $8.3(4.4-14.5)$ & $0.40-403.00$ \\
\hline Thyroglobulin antibody $(\mathrm{up}$ to 115$) \mathrm{IU} / \mathrm{ml}$ & $54.5(20.0-89.5)$ & $8.00-1190.00$ \\
\hline Median urinary iodine $(\mu \mathrm{g} / \mathrm{dl})$ & $55(41.0-76.0)$ & $20.00-200.00$ \\
\hline
\end{tabular}

This table shows that TPO Ab median was 8.3(4.4-14.5) mg/dl, Thyroglobulin Ab median was: $54.5(20.0-89.5) \mathrm{IU} / \mathrm{ml}$ and

median urinary iodine was 55(41.0-76.0) $\mu \mathrm{g} / \mathrm{dl}$

Table (5): Categorization of patients according to their median urinary iodine excretion and its use as indicator to dietary iodine intake.

\begin{tabular}{|l|c|c|}
\hline \multicolumn{1}{|c|}{ Parameter } & Urinary iodine level & Number \\
\hline Insufficient & $<150 \mu \mathrm{g} / \mathrm{l}$ & 99 \\
\hline Adequate & $150-249$ & 1 \\
\hline More than necessary & $250-499$ & None \\
\hline Excessive & $>/ 500$ & None \\
\hline
\end{tabular}

This table shows that 99 females had and none showed more than necessary insufficient iodine intake (urinary iodine intake(urinary iodine level (250-499) $\mu \mathrm{g} / \mathrm{l}$ ) level less than $150 \mu \mathrm{g} / \mathrm{l}$ ), one had adequate or excessive intake(urinary iodine level intake(urinary iodine level (150-249) $\mu \mathrm{g} / 1 \mathrm{l}) \quad$ more than $500 \mu \mathrm{g} / \mathrm{l}$.)

Table (6): Neck ultrasound of the studied patients

\begin{tabular}{|l|c|c|}
\hline \multicolumn{1}{|c|}{ Neck ultrasound results } & No. & $\%$ \\
\hline 1-Normal thyroid volume & 94 & $94.0 \%$ \\
\hline 2-Increased thyroid volume & 6 & $6.0 \%$ \\
\hline 2a)Thyroid Solitary nodule & 4 & $4.0 \%$ \\
\hline 2b)Diffuse goiter & 2 & $2.0 \%$ \\
\hline
\end{tabular}

This table shows that it was normal thyroid Solitary nodule $4 \%$, and diffuse thyroid volume in $94 \%$ and increased goiter $2 \%$.

volume in the remaining $6 \%$ subdivided into

Table (7): Correlation between demographic, anthropometric data and median urinary iodine: iodine6:

\begin{tabular}{|l|c|c|}
\hline \multirow{2}{*}{} & \multicolumn{2}{|c|}{ Median urinary iodine } \\
\cline { 2 - 3 } & $\mathrm{R}$ & $\mathrm{p}$-value \\
\hline Age & $-0.198^{*}$ & 0.048 \\
\hline Week of pregnancy & $-0.255^{*}$ & 0.010 \\
\hline Weight (at beginning of pregnancy) & -0.089 & 0.379 \\
\hline Height & -0.139 & 0.168 \\
\hline BMI & 0.006 & 0.949 \\
\hline SBP & 0.113 & 0.265 \\
\hline DBP & -0.079 & 0.437 \\
\hline
\end{tabular}

This table shows that there was a urinary iodine and $\mathrm{BMI}$

$(\mathrm{P}>0.05, \mathrm{r}$ Significant negative correlation between the age and urinary iodine $(\mathrm{p}<0.05 ., \mathrm{r}-$ 0,198), Significant negative correlation between the gestational age (in weeks) and urinar urinary iodine $(\mathrm{p}<0.05, \mathrm{r}-0.255)$, Non significant positive correlation between 0.006).,SBP $(\mathrm{P}>0.05, \mathrm{r} 0.113)$

And Non significant negative correlation between urinary iodine and Weight $(\mathrm{p}>0.05, \mathrm{r}-0.089)$, height $(\mathrm{p}>0.05, \mathrm{r}-$ $0.139)$ and, DBP ( $p>0.05, \mathrm{r}-0.079)$. 
Rania sayed Abd Elbaky, et al.,

Table (8): Correlation between laboratory data and median urinary iodine.

\begin{tabular}{|l|c|c|}
\hline \multirow{2}{*}{} & \multicolumn{2}{|c|}{ Median urinary iodine } \\
\cline { 2 - 3 } & $\mathrm{R}$ & $\mathrm{p}$-value \\
\hline TSH (0.3-5.5) & -0.139 & 0.167 \\
\hline FT4 (0.8-1.76) & 0.151 & 0.134 \\
\hline FT3 (2.3-4.2) & -0.052 & 0.608 \\
\hline TPO (up to 34) & 0.155 & 0.123 \\
\hline Thyroglobulin antibody (up to 115) & $0.243^{*}$ & 0.015 \\
\hline
\end{tabular}

This table shows that urine iodine and thyroglobin antibodies have a significant positive association ( $\mathrm{p} 0.05$ ). Urinary iodine has a non-significant positive connection with $\mathrm{f}$ T4 (p>0.05), a non-significant negative correlation with TSH, and a nonsignificant positive correlation with FT3 and TPO (p>0.05).

\section{DISCUSSION:}

During pregnancy, maternal iodine shortage and thyroid dysfunction are linked to a variety of negative consequences. Because the fetal thyroid does not mature until 13-15 weeks of pregnancy, the fetus is completely reliant on the maternal thyroid hormone supply throughout the first two trimesters of pregnancy $^{(7)}$.

Urinary iodine was first proposed in 1990 as a useful biochemical biomarker for assessing recent dietary iodine consumption and determining iodine status in the general population. After a technical meeting in 1992, the current urine iodine cut-off values for deficiency were first published in Indicators for evaluating iodine deficiency diseases and associated management programs by salt iodization $^{(8)}$.

Thyroid hormone synthesis requires iodine, and sufficient thyroid hormone production is necessary for brain development. The amount of iodine in many people's diets is less than the recommended level ${ }^{(9)}$.

This deficit is more common in pregnant women due to an increase in iodine requirements, which is mostly due to an increase in renal iodide clearance and fetal iodine requirements ${ }^{(10)}$. Women who get enough iodine before and during pregnancy have enough intra thyroidal iodine reserves and have no trouble adjusting to the higher demand for thyroid hormone during pregnancy. Total-body iodine levels in these women stay constant during pregnancy. Totalbody iodine reserves, as measured by urine iodine levels, drop progressively from the first to the third trimester of pregnancy in areas of mild to severe iodine shortage ${ }^{(11)}$.

Iodine deficiency (ID) during pregnancy has been linked to neurodevelopmental problems in children. As a result, there has been a lot of attention in recent years on the possible need for individual iodine-containing supplement consumption among pregnant women $^{(12)}$.

The gold standard for assessing iodine nutrition at the population level is urine iodine concentration (UIC) ${ }^{(13)}$. Because serum TSH is primarily influenced by the level of circulating thyroid hormone, which in turn reflects iodine consumption, it can be used as an indication of iodine nutrition ${ }^{(14)}$.

The aim of work of the current study was to assess the level of urinary iodine in 1st trimester of pregnancy and its relation to thyroid hormones and autoimmune thyroid profiles.

The study included 100 healthy pregnant females in their 1 st trimester of pregnancy their age range is from 18 to 40 years old. They were collected from Obstetric and Gynecology Department El Demerdash hospital and Dar El Shefa Hospital in the 
period from September 2020 to November 2020.

In our study the mean TSH was $(1.9 \pm 0.98) \mathrm{mIU} / \mathrm{ml}$, the mean FT4 was $(1.04 \pm 0.98) \mathrm{ng} / \mathrm{dl}$ and the mean FT3 was (3.02 \pm 0.68$) \mathrm{ng} / \mathrm{dl}$ with prevalence of subclinical hypothyroidism $25 \% \quad$ (TSH $>4$ $\mathrm{mIU} / \mathrm{ml}$ ) according to the Endocrine Society clinical practice guidelines (ATA 2017) (Alexander et al., 2017) with mean TSH value $(8.10 \pm 4.91) \mathrm{m}$ IU/ $\mathrm{ml}$, mean FT4 $(1.15 \pm 0.33) \mathrm{ng} / \mathrm{dl}$ and the mean FT3(2.91 \pm 0.63$) \mathrm{ng} / \mathrm{dl})$ which coincide with Marwaha et al. (2008) who reported that the median TSH value was 2.1(0.04-10.8) $\mathrm{MIU} / \mathrm{ml}$ in the first trimester with prevalence of subclinical hypothyroidism $29.9 \%$ on a study conducted on 331 pregnant Indian females where they were divided into 107 in first trimester, 137 in second trimester and 87 in third trimester.

In our study the mean TSH was $(1.9 \pm 0.98) \mathrm{mIU} / \mathrm{ml}$, the mean FT4 was $(1.04 \pm 0.98) \mathrm{ng} / \mathrm{dl}$ and the mean FT3 was $(3.02 \pm 0.68) \mathrm{ng} / \mathrm{dl}$ with prevalence of subclinical hypothyroidism 25\%(TSH $>4$ $\mathrm{mIU} / \mathrm{ml}$ ) according to the Endocrine Society clinical practice guidelines (ATA 2017) Alexander et al. (15) with mean TSH value $(8.10 \pm 4.91) \mathrm{m}$ IU/ $\mathrm{ml}$, mean FT4 $(1.15 \pm 0.33) \mathrm{ng} / \mathrm{dl}$ and the mean FT3(2.91 \pm 0.63$) \mathrm{ng} / \mathrm{dl})$ which coincide with Marwaha et al (16) who reported that the median TSH value was 2.1(0.04-10.8) $\mathrm{MIU} / \mathrm{ml}$ in the first trimester with prevalence of subclinical hypothyroidism $29.9 \%$ on a study conducted on 331 pregnant Indian females where they were divided into 107 in first trimester, 137 in second trimester and 87 in third trimester.

Xing et al. ${ }^{(17)}$, on the other hand, studied the thyroid functions in 2540 Chinese women with normal pregnancies, 398 of whom were in their first trimester, and found that the median TSH was normal according to the ATA guidelines. This study was conducted in Henan, China, which has an adequate supply of iodine. TSH levels were shown to be substantially lower in pregnant women compared to non-pregnant women, according to Yan et al. ${ }^{(18)}$.

Between September 2011 and December 2011, a study of 168 pregnant women in various trimesters (85 in the first trimester) who visited the outpatient obstetric clinic at Ain Shams University Hospital (Cairo, Egypt) for antenatal care found that 56 percent $(\mathrm{n}=$ 94) of the patients (all pregnant females) had $\mathrm{TSH}>2.5 \mathrm{~m} \mathrm{IU/L}{ }^{(19)}$.

Also another study done by Elebrashy et $\boldsymbol{a l}^{(20)}$ conducted on 150 normal pregnant Egyptian females, recruited from Cairo University Hospital 50 of them in the first trimester with $\mathrm{TSH}$ ranges were $0.21-1.7$ $\mathrm{mIU} / \mathrm{L}$.

In the present study, the median TPO $a b$ in the studied patients was of normal range and no correlation between TPO Abs and UI, TSH, FT4 nor FT3 which disagrees with a study done by Amouzegar et al. $^{(21)}$ was studied thyroid functions in 203 pregnant women reported that there were $19(9.3 \%)$ pregnant females had positive TPO Ab in their first trimester and no correlation between TPO Abs and UI nor FT4.

In a study conducted by Springer et $a .^{(22)}$ on 5520 randomly chosen pregnant females in their first trimester of pregnancy, TPO ab>143 kIU/l was found to be elevated in 549 women (about 9.95 percent ). Elebrashy et al. ${ }^{(20)}$ conducted a study on 150 normal pregnant Egyptian females recruited from Cairo University Hospital Antenatal Care Clinic (50 in each trimester) and a control group of 40 age-matched nonpregnant females. The mean TPO was likewise high in this research, which was conducted using an enzyme-linked immunosorbent assay with a high specificity but poorer sensitivity than our immunofluorescence technique for TPO abs detection. 
In the current study, the median anti thyroglobulin antibody is within the normal range, and there is a significant positive correlation between ATA and UIC (urinary iodine concentration), whereas in a study of 191 pregnant women (case) and 62 nonpregnant women (control), anti thyroglobulin antibody values were high in 3.7 percent of cases compared to reference values, and there was no correlation between ATA and UIC ${ }^{(23)}$.

A study was also done on 85 women who were followed up on at $8,12,16,20,28$, and 36 weeks throughout their pregnancy. Anti thyroglobulin concentrations were greater in early pregnancy (pregnancy at 8 weeks vs non pregnancy: $11.42 \mathrm{ng} / \mathrm{ml}$ vs $8.8 \mathrm{ng} / \mathrm{ml}, \mathrm{P} 0 \bullet 01$ ), according to a study of 132 non pregnant women from Dalian, China. At varying UIC levels, there were no relationships between UIC and Thyroglobulin abs ${ }^{(24)}$.

In the current study, the median urinary iodine decreased in the studied patients, with a percentage of $99 \%$ for iodine deficiency, which was in agreement with Kedir et al. ${ }^{(25)}$, who reported that among 52 subjects, 9 had adequate iodine and 43 had deficient iodine, with an iodine deficiency prevalence of 86 percent, in their study to detect iodine deficiency among pregnant women in Eastern Ethiopia.

In the same line, Aguayo et al. $^{(26)}$ found that the median UIC was low $(88.5 \mathrm{~g} / \mathrm{l})$ in their study of 2104 women in their first trimester in the north of Spain, and that there was no relationship between UIC and FT4 or TSH. A similar finding was reported by Gowachirapant et al. ${ }^{(27)}$ from Thailand, where the median UIC was also low (108 $\mathrm{g} / \mathrm{l})$.

De Zoysa et al. ${ }^{(28)}$, on the other hand, found that the median urine iodine content was (sufficient) 170 microgram/l in their research. This research involved 425 pregnant women in the Galle area of Sri Lanka's south. Sri Lanka was classified as a nation with an acceptable iodine nutrition status, with $>90$ percent of the population using enough iodized salt. Sri Lanka was also deemed to have met all of the WHO/ICCIDD criteria for monitoring progress toward the long-term eradication of IDD.

Also a study done in Taiwan 2018 conducted on 257 pregnant women among them there were 16 women in their first trimester. Urinary iodine concentration UIC was high (146.3-777.8) 5 subjects had deficient, 2 adequate, 4 above requirements and 5 excessive with percentage of iodine deficiency only (31\%) may due to the population in this study mainly resides in the Taipei metropolitan area and surrounding countries generally are socioeconomically wealthier than the rest of Taiwan also receive longer education and so more nutritional support ${ }^{(29)}$.

Simpong et $\boldsymbol{a}^{(30)}$ conducted a prospective study on 125 pregnant females with an expected gestational age of 11 weeks at Sefwi Wiawso, a periurban setting in Ghana's western region, from August 2015 to May 2016. Their UIC was more than requirements in (10) subjects, excessive in (33), sufficient in (23) and deficient in (59), with a percentage of iodine deficiency among them.

In a study done on 50 Indian pregnant women in their first trimester by Grewal et al. $^{(31)}$, the median urinary iodine was high, and just $2 \%$ of the pregnant women had iodine shortage, with almost $80 \%$ having more than sufficient levels. Although the cause of these disparities is unknown, ethnic differences in food structure or the degree of overall iodine shortage may play a role.

This may be attributed to an improvement in the implantation of USI (universal salt iodization), but other factors such as the technique of urine iodine estimation, selectivity of the research population, and nonsalt sources of iodine may have contributed to the increased MUI over time ${ }^{(31)}$. 
To our knowledge, no studies on the measurement of urine iodine levels in healthy females during the first trimester of pregnancy have been done in Egypt. The median iodine level in our urine was 55, the mean TSH was 1.90.98, and the mean FT4 was 1.040 .41$.

The results of a national health and nutrition examination survey in the United States revealed that UI levels were higher in the second and third trimesters than in the first trimester, and that the median urine iodine concentration (UIC) in the United States fell from $320 \mathrm{~g} / \mathrm{l}$ to $144 \mathrm{~g} / \mathrm{l}$ between 1971 and 2010, while pregnancy median UIC fell from $153 \mathrm{~g} / \mathrm{l}$ between 2001 and 2006 to insufficient levels of $150 \mathrm{~g} / \mathrm{l}$ between 2001 and $2006^{(32 \& 33)}$.

Despite the fact that some countries' iodine status was adequate across all age groups, data from a survey of 21 European countries in 2014 revealed that 13/21 countries had inadequate iodine intake with low UI levels during pregnancy due to poor access to iodized foodstuffs and insufficient monitoring of iodine nutrition status ${ }^{(34)}$.

In terms of iodine status surveys in various parts of the world, Caballero ${ }^{(35)}$ conducted a cross sectional research on 100 pregnant females in Venezuela and found that urine iodine levels were acceptable with a low prevalence of insufficiency ( 25 percent ) In contrast to a study done in Turkey by Cetinkaya et al. ${ }^{(36)}$, a study done in England by Bath et $\boldsymbol{a l} .{ }^{(37)}$, a study done in Bangladesh by Shamim et al. ${ }^{(38)}$, a study done in Spain by Aguayo et al. ${ }^{(26)}$, and a study done in Iran by Amouzegar et al. ${ }^{(21)}$, all those studies reported insufficiency.

In our study, normal thyroid volume was found in $94 \%$ of the women and abnormal in $6 \%$ (solitary nodule $4 \%$ and goitre $2 \%$ ), which contrasts with a study conducted by De Zoysa et al. ${ }^{(28)}$ on 425 pregnant women in Galle district, Sri Lanka, which found that 67 $(16.0 \%)$ of the women had palpable or visible goitres and 67 (16.0\%) had solitary nodules.
Ollero et al. $^{(39)}$ studied 400 pregnant women in a prospective, longitudinal research. Thyroid nodules were found in $28.8 \%$ of pregnant women $(n=115)$, and those with nodules had continuously lower TSH levels throughout the pregnancy and higher fT4 levels in the first trimester ( $p 0.001$ ).

There was no correlation between increased thyroid volume and both $\mathrm{ft} 4$ and free t3 levels in our study, but $50 \%$ of those with increased thyroid volume also had increased TSH levels, which agrees with Fister et al. ${ }^{(40)}$ who found that thyroid volume increases during pregnancy and decreases after delivery in the iodine-deficient republic of Slovania. They also discovered that variations in volume are linked to variations in BMI and TSH.

In contrast to a cross sectional study by Gyamfi et al. ${ }^{(41)}$ to assess urinary iodine concentration and thyroid volume in 222 pregnant women in various trimesters who attended a clinic at KNUST Hospital in Ghana, which found a clinically significant negative weak correlation between urinary iodine and thyroid volume, there is no significant relationship between thyroid volume and median urinary iodine (MUI) in our study.

There was no significant correlation between median urinary iodine and weight, height, or BMI in the current study, which agrees with a prospective study designed to assess iodine nutrition during pregnancy with both urine iodine concentration and thyroid determinants among 425 pregnant women from Galle district, Sri Lanka, which reported that the first trimester urinary iodine was higher than the second trimester and the first trimester urinary iodine level has only a significant positive correlation $(r=0.124, p=$ 0.02 ) with women's weight, but not with any other demographic parameters at the study entry done according to De Zoysa et al. ${ }^{(28)}$.

There was no significant association between median urinary iodine and TSH, FT4, or FT3 in our investigation, which corresponds 
with De Zoysa et al. ${ }^{(28)}$, who found that pregnant women with mild iodine shortage also have normal TSH levels. Maintaining median serum TSH, which is contrary to Fuse et $\boldsymbol{a l} .{ }^{(42)}$, who found that urinary iodine excretion was $215.5 \mathrm{~g} / \mathrm{liter}$ in the first trimester in 563 Japanese pregnant women. During pregnancy, the maternal UIC and serum TSH had a positive correlation.

In our research, the urine iodine level and age had a strong negative association. Significant negative correlation between urinary iodine and gestational age (in weeks) (p0.01), which agrees with De Zoysa et al. ${ }^{(28)}$ who found that the median UIC of women decreased significantly as pregnancy progressed ( $\mathrm{p} 0.001$ ), and Significant positive correlation between urinary iodine and thyroglobin antibody (p0.015), which agrees with Amouzegar et al. ${ }^{(21)}$.

\section{Conclusion:}

In our study, the urine iodine level and age had a strong negative association. Significant negative correlation between urinary iodine and gestational age (in weeks) (p0.01), and Significant positive correlation between urinary iodine and thyroglobin antibody (p0.015).

\section{Recommendation:}

Further studies are needed to clarify the potential impact of women's low iodine level and benefits or adverse effects of iodine supplementation on the health of the mother and her offsprings.

\section{REFERENCES:}

1. Rinaldi MD, Stagnaro-Green AS. Thyroid disease and pregnancy: Degrees of knowledge. Thyroid 2007;17:747-53.

2. Rodriguez-Diaz E, Pearce EN. Iodine status and supplementation before, during, and after pregnancy. Best Practice \& Research Clinical Endocrinology \& Metabolism. 2020; 34(4): 101430.
3. Leung AM, Pearce EN, Braverman LE. Iodine content of prenatal multivitamins in the United States. New England Journal of Medicine. 2009; 360(9):939-40.

4. Melse-Boonstra A and Mackenzie I. Iodine deficiency, thyroid function and hearing deficit: a review. Nutrition research reviews. 2013; 26(2):110-7.

5. Gibson RS. Principles of nutritional assessment. Oxford university press, USA. 2005.

6. WHO. Assessment of iodine deficiency disorders and monitoring their elimination: Indicators of impact. 2007; Page 28.

7. Kerver JM, Pearce EN, Ma T, Gentchev M, Elliott MR, Paneth N. Prevalence of inadequate and excessive iodine intake in a US pregnancy cohort. American Journal of Obstetrics and Gynecology. 2021; 224(1):82e1.

8. World Health Organization. Urinary iodine concentrations for determining iodine status in populations. World Health Organizations; 2017.

9. Lazarus JH. The importance of iodine in public health. Environmental geochemistry and health. 2015; 37(4):605-18.

10. Pearce EN, Andersson M, Zimmermann MB. Global iodine nutrition: where do we stand in 2013? Thyroid 2013; 23:523-528.

11. Gargari SS, Fateh R, Bakhshali-Bakhtiari M, Saleh M, Mirzamoradi M, Bakhtiyari M. Maternal and neonatal outcomes and determinants of iodine deficiency in third trimester of pregnancy in an iodine sufficient area. BMC pregnancy and childbirth. 2020; 20(1):1-9.

12. Andersen SL and Laurberg P. Iodine supplementation in pregnancy and the dilemma of ambiguous recommendations. European thyroid journal. 2016; 5(1):35-43.

13. Brucker-Davis F, Ferrari P, Gal J, Berthier F, Fenichel P, Hieronimus S. Iodine status has no impact on thyroid function in early healthy pregnancy. Journal of thyroid research. 2012; 1-7.

14. Zimmermann MB. Iodine deficiency. Endocrine reviews. 2009; 30(4):376-408. 
15. Alexander EK, Pearce EN, Brent GA, et al. Guidelines of the American Thyroid Association for the Diagnosis and Management of Thyroid Disease During Pregnancy and the Postpartum. Thyroid 2017; 27:315-89.

16. Marwaha RK, Chopra S, Gopalakrishnan S, Sharma B, Kanwar RS, Sastry A, Singh S. Establishment of reference range for thyroid hormones in normal pregnant Indian women. BJOG: An International Journal of Obstetrics \& Gynaecology. 2008; 115(5):602-6.

17. Xing J, Yuan E, Li J, Zhang Y, Meng X, Zhang X, Rong S, Lv Z, Tian Y, Jia L. Trimester-and assay-specific thyroid reference intervals for pregnant women in China. International journal of endocrinology. 2016; 1-6.

18. Yan YQ, Dong ZL, Dong L, Wang FR, Yang $X M$, Jin XY, Lin LX, Sun YN, Chen ZP. Trimester-and method-specific reference intervals for thyroid tests in pregnant Chinese women: methodology, euthyroid definition and iodine status can influence the setting of reference intervals. Clinical endocrinology. 2011; 74(2):262-9.

19. Ahmed IZ, Eid YM, El Orabi H, Ibrahim HR. Comparison of universal and targeted screening for thyroid dysfunction in pregnant Egyptian women. European journal of endocrinology. 2014; 171(2):285-91.

20. Elebrashy I, Eldein HA, Abd-Elstar H, Ghanem N, Mousa S, Assem M, Rashed L, Salit M, Abd-Elraoof M, Dorgham A, Mansour A. Assessment of thyroid functions and thyroid volume in normal pregnant Egyptian females. Gynecological Endocrinology. 2019; 122-125.

21. Amouzegar A, Khazan M, Hedayati M, Azizi F. An assessment of the iodine status and the correlation between iodine nutrition and thyroid function during pregnancy in an iodine sufficient area. European journal of clinical nutrition. 2014; 68(3):397-400.

22. Springer D, Zima T, Limanova Z. Reference intervals in evaluation of maternal thyroid function during the first trimester of pregnancy. European Journal of Endocrinology. 2009; 160(5):791.
23. Chaudhary LN, Khatiwada S, Gelal B, Gautam S, Lamsal M, Pokharel H, Baral N. Iodine and thyroid function status, and antithyroid peroxidase antibody among pregnant women in eastern Nepal. Journal of Nepal Health Research Council. 2017; 15(2):114-9.

24. Zhang X, Li C, Mao J, Wang W, Xie X, Peng S, Wang Z, Han C, Zhang X, Wang D, Fan C. Gestation-specific changes in maternal thyroglobulin during pregnancy and lactation in an iodine-sufficient region in China: a longitudinal study. Clinical endocrinology. 2017; 86(2):229-35.

25. Kedir H, Berhane Y, Worku A. Subclinical iodine deficiency among pregnant women in Haramaya district, Eastern Ethiopia: a community-based study. Journal of Nutrition and Metabolism. 2014; 1-8.

26. Aguayo A, Grau G, Vela A, Aniel-Quiroga A, Espada M, Martul P, Castano L, Rica I. Urinary iodine and thyroid function in a population of healthy pregnant women in the North of Spain. Journal of trace elements in medicine and biology. 2013; 27(4):302-6.

27. Gowachirapant $S$, Winichagoon $P$, Wyss L, Tong B, Baumgartner J, Melse-Boonstra A, Zimmermann MB. Urinary iodine concentrations indicate iodine deficiency in pregnant Thai women but iodine sufficiency in their school-aged children. The Journal of nutrition. 2009; 139(6):1169-72.

28. De Zoysa E, Hettiarachchi M, Liyanage C. Urinary iodine and thyroid determinants in pregnancy: a follow up study in Sri Lanka. BMC pregnancy and childbirth. 2016; 16(1):1-6.

29. Huang CJ, Tseng CL, Chen HS, Hwu CM, Tang KT, Won JG, Shih CW, Yeh CC, Yang $\mathrm{CC}$, Wang FF. Iodine nutritional status of pregnant women in an urban area of northern Taiwan in 2018. Plos one. 2020; 15(5): e0233162.

30. Simpong DL, Awuku YA, Kye-Amoah KK, Morna MT, Adoba P, Anin SK, Adu P. High iodine deficiency among pregnant women in Periurban Ghana: a hospital-based longitudinal study. Journal of nutrition and metabolism. 2018; 1-6. 
31. Grewal E, Khadgawat R, Gupta N. Assessment of iodine nutrition in pregnant north Indian subjects in three trimesters. Indian journal of endocrinology and metabolism. 2013; 17(2):289.

32. Caldwell KL, Pan Y, Mortinsen ME, et al. Iodine, status in pregnant women in the National Children's Study and in U.S. women (15-44 years), NHANES 2005-2010. Thyroid. 2013; 23(8):927-37.

33. Sullivan KM, Perrine CG, Pearce EN, Caldwell KL. Monitoring the iodine status of pregnant women in the United States. Thyroid. 2013; 23(4):520-531.

34. Lazarus JH. Iodine status in Europe in 2014. European thyroid journal. 2014;3(1):3-6.

35. Caballero L. Yoduria en escolares y embarazadas del estado Trujillo, Venezuela 2007-2008 Urinary Iodine in school children and pregnant women of Trujillo state, Venezuela 2007-2008. Raem No. 2011; 48(4):206-11.

36. Cetinkaya K, Ingec M, Cetinkaya S, Kaplan I. Iodine deficiency in pregnancy and in women of reproductive age in Erzurum, Turkey. Turkish Journal of Medical Sciences. 2012; 42(4):675-80.

37. Bath SC, Steer CD, Golding J, Emmett P, Rayman MP. Effect of inadequate iodine status in UK pregnant women on cognitive outcomes in their children: Results from the Avon Longitudinal Study of Parents and Children (ALSPAC). Lancet [Internet]. 2013; 382(9889):331-7
38. Shamim AA, Christian P, Schulze KJ, Ali H, Kabir A, Rashid M, Labrique A, Salamatullah Q, West Jr KP. Iodine status in pregnancy and household salt iodine content in rural Bangladesh. Maternal \& child nutrition. 2012; 8(2):162-73.

39. Ollero MD, Toni M, Pineda JJ, Martínez JP, Espada M, Anda E. Thyroid function reference values in healthy iodine-sufficient pregnant women and influence of thyroid nodules on thyrotropin and free thyroxine values. Thyroid. 2019; 29(3):421-9.

40. Fister P, Gaberšček S, Zaletel K, Krhin B, Geršak K, Hojker S. Thyroid volume changes during pregnancy and after delivery in an iodine-sufficient Republic of Slovenia. European Journal of Obstetrics \& Gynecology and Reproductive Biology. 2009; 145(1):45-8.

41. Gyamfi D, Wiafe YA, Danquah KO, Adankwah E, Amissah GA, Odame A. Urinary iodine concentration and thyroid volume of pregnant women attending antenatal care in two selected hospitals in Ashanti Region, Ghana: a comparative crosssectional study. BMC pregnancy and childbirth. 2018; 18(1):1-9.

42. Fuse Y, Ohashi T, Yamaguchi S, Yamaguchi M, Shishiba Y, Irie M. Iodine status of pregnant and postpartum Japanese women: Effect of iodine intake on maternal and neonatal thyroid function in an iodinesufficient area. J Clin Endocrinol Metab. 2011; 96(12):3846-54 


\section{تقييم مستوى الايودين بالبول وعلاقته بوظائف الغدة الدرقية فى بعض الإناث الحوامل المصريات فى الفصل

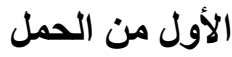

'رانيا سيد عبد الباقى، ' ميرهان سامي نصر، ' احمد علي الانور، ' علياء عبد الحميد عبد العظيم، ' احمد محمد الأين الخلفية: اضطر ابات الغدة الدرقية وهى أكثر اضطر ابات الغدد الصماء شيوعا التى تصيب النئ النساء خلال سنو اتهن

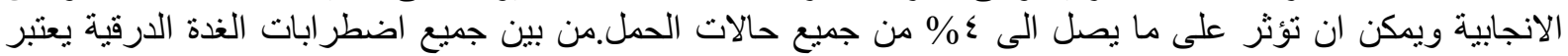

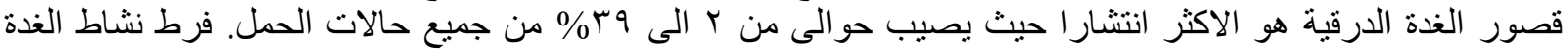

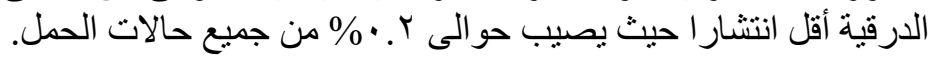

الهوف من العمل: تقييم مستوى اليود البولي في الثلث الأول من الحمل و علاقته بهرمونات الغدة الغدة الدرقية.

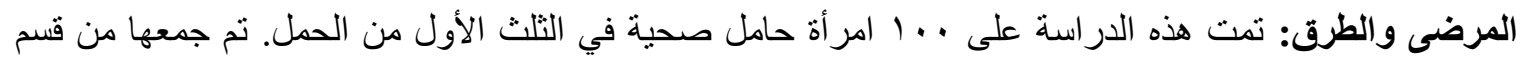

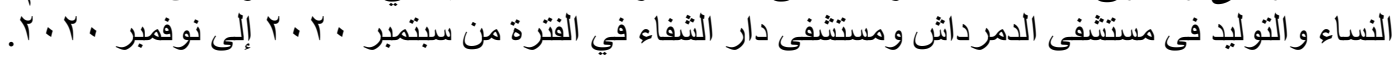

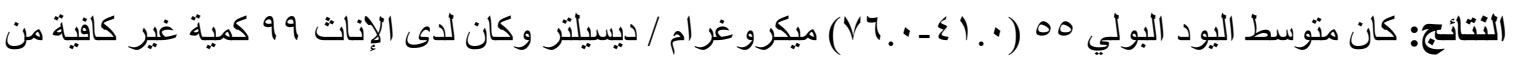

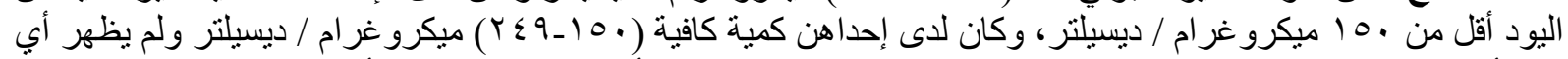

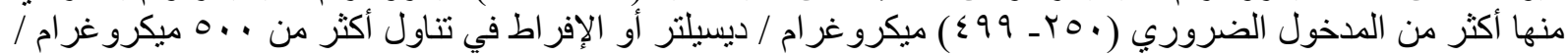

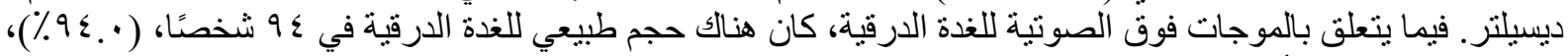

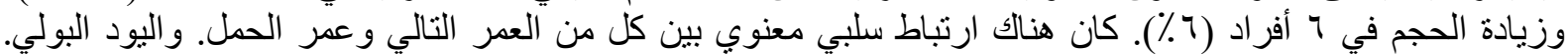

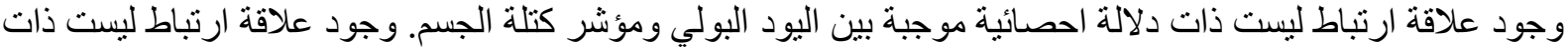

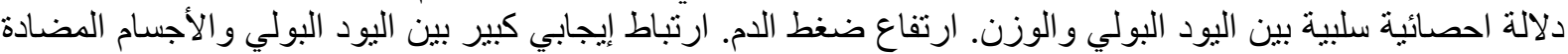

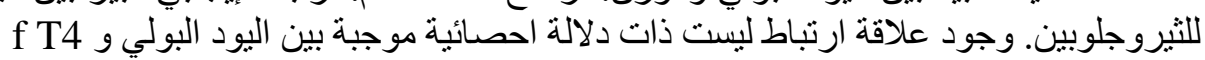

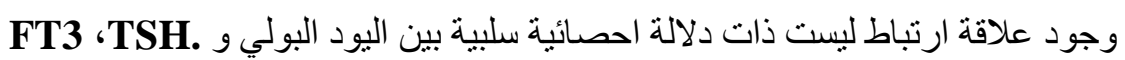

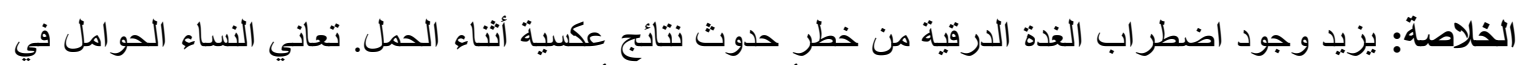

مصر بشكل عام من عدم كفاية إفراز اليود في البول خلال الأشهر الثلاثة الأولى من الحمل. ارتباط إيجابي كبير بين اليود الثاء البولي و الأجسام المضادة للثنيروجلوبين. 